\title{
Disentangling the Effects of Applicant Defensive Impression Management Tactics in Job Interviews
}

\author{
Wei-Chi Tsai*, Tun-Chun Huang**, Chih-Yun Wu*** and \\ I-Hsuan Lo*****
}

\begin{abstract}
*Department of Business Administration, National Chengchi University, Taipei, Taiwan
**Department of Business Administration, National Taiwan University of Science and Technology, Taipei, Taiwan ***Department of Business Administration, Tung-Hai University, No. 181, Section 3, Taichung Harbor Road, TaiChung 407, Taiwan. annacywu@thu.edu.tw

*****Yang Ming Marine Transport Corp., Keelung, Taiwan
\end{abstract}

This study explores (1) the effects that three kinds of applicant defensive impression management (IM) tactics (apologies, justifications, and excuses) have on interviewer evaluation and (2) the moderating effects that two types of interviewer negative concerns (competence-related and integrity-related concerns) have on the aforementioned relationship. Two hundred and one managers from Taiwan participated in this study by watching a simulated interview. Compared with the control group, applicants using defensive IM tactics received higher interviewer ratings when negative concerns surfaced. Moreover, the type of interviewer negative concern moderated the effects of defensive IM tactics. All three tactics had similar effects on interviewer evaluation when the concern was competence related. Apology was, however, the most effective tactic when the concern was integrity related.

\section{Introduction}

mpression management (IM) tactics have been defined as 'behaviors individuals employ to protect their self-images, influence the way they are perceived by significant others, or both' (Wayne \& Liden, 1995, p. 232). Accordingly, IM tactics can be classified as assertive (tactics used to actively construct a favorable image) or defensive (tactics used to passively protect or repair one's image). Among them, defensive IM tactics such as apologies (accepting responsibility for a negative event, offering to make things right, and promising to do better in the future), justifications (accepting responsibility for negative outcomes but not the negative implications), and excuses (shifting responsibility to some external causes) are found to protect or repair one's image from damage in personal-communication contexts (e.g., Shaw, Wild, \& Colquitt, 2003; Tata, 2002a). However, studies that examined the effect of IM in the job interview context primarily focused on assertive IM because researchers argued that defensive IM was used less frequently than was assertive IM (e.g., Kacmar, Delery, \& Ferris, 1992; Stevens \& Kristof, 1995).

The use of defensive IM in job interviews is perhaps more common than we thought. For example, Ellis, West, Ryan, and DeShon (2002) found that 77 out of 119 applicants $(64.7 \%)$ participating in their simulated interviews spontaneously used at least one form of defensive IM tactic when interviewer negative concerns surfaced in interviews (e.g., the interviewer questioned the applicant's unfavorable performance on a previous group task). We define 'interviewer negative concern' as the interviewer's preoccupation with an applicant's past unfavorable behavioral choices or performance. By raising their negative concerns about applicants, interviewers create in most of the applicants a feeling that they should effectively address these concerns in order to receive desired job offers. In such a circumstance, applicants may adopt defensive IM tactics in order to repair their damaged image.

Two recent studies have examined the relationship between uses of defensive IM tactics and interviewer evaluation (Peeters \& Lievens, 2006; Van Iddekinge, 
McFarland, \& Raymark, 2007). Nonetheless, instead of being examined individually, different types of defensive IM tactics were aggregated in these studies to form a composite score and linked to interviewer evaluations. Although Peeters and Lievens found a positive effect of defensive IM on interviewer evaluation, important questions such as (1) whether all types of defensive IM tactics contribute to the reinstatement of interviewer evaluations and (2) under what circumstances these tactics are most effective remained unanswered. These questions cannot be easily answered unless we disentangle the effects of different defensive IM tactics. Therefore, a major objective of the present study is to differentiate the effects of three defensive IM tactics (apologies, justifications, and excuses) from one another and examine their effects on interviewer evaluations.

In addition, on the basis of both the nature of interviewer negative concerns and the characteristics of each defensive IM tactic, we have proposed that the type of interviewer negative concern may moderate the relationship between defensive IM tactics and interviewer evaluations. Thus, the present study goes beyond the examination of the main effects of applicant defensive IM tactics and contributes to the IM literature by identifying how situational factors (i.e., types of interviewer negative concerns) interact with applicant defensive IM tactics in influencing the interviewer evaluations of applicants. To date, little research has been conducted regarding the boundary conditions of applicant defensive IM tactics. This research serves as a first step toward building a more comprehensive model illustrating the role of defensive IM tactics in employment interviews.

\section{Theory and hypotheses}

\subsection{Defensive IM}

One can employ defensive IM tactics to repair one's image after it has been damaged or questioned (Stevens \& Kristof, 1995). The core of this contention lies in 'explanation,' which means to elaborate on the reasons for negative outcomes (Shaw et al., 2003). Apologies, justifications, and excuses have proven to be effective IM tactics for restoring damaged relationships in social interactions. For example, Tata (2002a) showed that each of these tactics helps people to rehabilitate their images that have suffered damage owing to work teams' perception of these people as loafers. In addition, the use of these defensive IM tactics was found to mitigate employees' anger toward negative performance feedback and to increase perceived interpersonal fairness (Tata, 2002b).

When interviewers raise any negative concern in an interview, applicants will perceive a discrepancy between current and desired self-images and would thus be motivated to use defensive IM tactics to reinstate their damaged images (Bozeman \& Kacmar, 1997; Roberts,
2005). Recently, Peeters and Lievens (2006) found that applicants in behavioral description interviews used significantly more defensive IM tactics. More important, they found a positive relationship between applicants' uses of defensive IM tactics and interviewer evaluations. However, what is left unanswered in Peeters and Lievens's study is whether or not each type of defensive IM tactic improves the interviewer's impression of the applicants, because in that study, applicants' uses of apology, justification, and excuse tactics were aggregated to form a composite score, namely, 'Defensive IM.' To date, research has shed substantial light on how specific types of assertive IM (e.g., self-promotion, other-focused, and exemplification tactics) help applicants create desired images and get job offers (see Bolino, Kacmar, Turnley, \& Gilstrap, 2008, for a review). In order to broaden our knowledge about the usefulness and effectiveness of defensive IM in job interviews, more attention should be paid to how each defensive tactic operates in this particular organizational context. Disentangling the effects of apologies, justifications, and excuses represents a good starting point.

By definition, defensive IM tactics help to reduce the applicant's personal responsibility for negative concern (i.e., excuses), to improve the interviewer's impression of the event under consideration (i.e., justifications), or to express the applicant's remorse and to assure the interviewer that a similar failure would not happen again (i.e., apologies). Although three defensive IM tactics may affect interviewer evaluations through different psychological processes, they all have the potential to mitigate the threat to the applicant's desired image - the threat caused by the interviewer's negative concern in the job-interview context. Hence, we propose the following hypothesis:

Hypothesis 1: When interviewer negative concerns surface in job interviews, applicants who use any type of defensive IM tactics (apologies, justifications, or excuses) will receive higher interviewer evaluations than applicants who do not use these tactics.

\subsection{The moderating effects of interviewer negative concerns}

Although the effects of defensive IM tactics have been examined in various contexts, there is no agreement on what tactic is most effective in addressing others' negative concerns. For example, in a teamwork situation, Tata (2002a) found that poor-reputation team members who apologized obtained a higher overall evaluation from other team members than those who gave justifications or made excuses for the suspect behavior. In contrast, Tata (2000) found that apologizers were judged as more blameworthy than justifiers or excusers in an employeeharassment situation. 
The inconsistent findings mentioned above, along with a nonsignificant relationship between a composite measure of defensive IM usage (the extent to which an applicant engages in apologies, justifications, and excuses) and interviewer evaluation reported by Van Iddekinge et al. (2007), suggest a need to explore possible moderators for the effectiveness of defensive IM tactics. Although relatively little information can be retrieved from Peeters and Lievens (2006) and Van Iddekinge et al. (2007), we were able to identify an obvious difference between Tata (2000) and Tata (2002a), namely, the nature of the negative concerns. The negative concerns that surfaced in Tata (2002a) can be described as performance problems or competence-related issues, whereas the negative concerns that surfaced in Tata (2000) were ethical concerns or integrity-related issues. Competence refers to a set of technical and interpersonal skills that are required for specific tasks (Butler \& Cantrell, 1984), while integrity refers to the work norms or ethical standards that should be followed by the members of an organization (Ones, Viswesvaran, \& Schmidt, 1993). People use these two criteria to form their expectations of others in daily interactions (Kim, Ferrin, Cooper, \& Dirks, 2004), and in a more specific context, voters use them to assess the extent to which a candidate can and will serve the public interest well (Fenno, 1978; McCurley \& Mondak, 1995). Similarly, interviewers will make efforts to evaluate the extent to which the applicant can and will serve organizational goals. Interviewers' employment decisions may reflect, in part, the interviewers' negative concerns regarding the applicant and the way the applicant deals with these concerns.

In job interviews, a competence-related negative concern implies that the applicant is lacking the ability to complete tasks in the future. This might lead interviewers to doubt the applicant's future success (Reeder \& Brewer, 1979). To dispel a given interviewer's competence-related concerns, applicants have to make the interviewer believe that they can perform requisite job tasks once they are hired. In contrast, when integrity-related concerns take hold in interviewers' minds, the interviewers question the likelihood that the applicant will adhere to a set of moral social orders or work ethics. Under such circumstances, applicants have to make the interviewer believe that they have nothing to do with the integrity-related negative event. This is because people seldom change their evaluations of others' integrity. As noted by Kim et al. (2004), once a person has been caught stealing, there is a lurking suspicion of this individual, even if he or she does not commit additional thefts in the next few years.

Although the limited research on the effectiveness of defensive IM tactics in the job interview context makes it difficult to establish a priori hypotheses regarding the order of tactic effectiveness in dealing with competenceand integrity-related concerns, several predictions can be made as to how these tactics interact with types of negative concerns to jointly predict interviewer evaluations. Differences among defensive IM tactics reflect the extent to which the actors provide information regarding future performance and the extent to which the actors bear the responsibility for the negative concern. Thus, applicants who apologize for the negative concern may receive better evaluations when the concern is competence related than when it is integrity related, because apology tactics imply that the actor not only admits responsibility for the event (such a statement may unfavorably influence interviewer evaluations when integrity-related concerns are under consideration; Reeder \& Brewer, 1979) but also promises to behave in a desired way in the future (such a promise may favorably influence interviewer evaluations when competence-related concerns are under consideration; Schweitzer, Hershey, \& Bradlow, 2006). In contrast, excuses may be more suitable than apologies for dealing with integrity-related concerns. This is because applicants who use excuse tactics do not accept responsibility for the integrity-related event. If applicants successfully make an interviewer believe they have no relationship with the cause of the integrity-related concern, they might receive more favorable evaluations than those who apologize and accept personal responsibility. Hence, we propose an exploratory hypothesis:

Hypothesis 2: The effects of applicant defensive IM tactics will depend on the type of interviewer negative concerns.

\section{Method}

In this study, we adopted an approach different from that of the two previous studies in the operationalization of applicant defensive IM tactics. Peeters and Lievens (2006) and Van Iddekinge et al. (2007) asked independent raters (I/O psychology doctoral or graduate students) to provide frequency counts of an applicant's assertive and defensive IM tactics in a mock interview. Researchers have suggested that these frequency counts may not be the most accurate way of describing applicants' uses of IM tactics (Godfrey, Jones, \& Lord, 1986), because interviewers and independent raters (e.g., doctoral or graduate students in the two previous studies) may have different frames of reference (Stevens \& Kristof, 1995).

Research participants in the current study took the role of interviewer and watched a simulated interview in which interviewers' negative concerns and applicants' defensive IM tactics were manipulated by the researchers; interviewers then provided their evaluations of the applicants. Two conditions had to be satisfied in order to demonstrate that applicants' defensive IM tactics affected interviewers' evaluations. First, research participants had to correctly identify the type of applicant IM tactics (i.e., successful manipulation checks). Second, the results of statistical analyses had to show positive relationships 
between applicants' defensive IM tactics and interviewers' evaluations. The design adopted in the current study enabled us to rule out alternative explanations and to fully capture the effects of defensive IM tactics on interviewer evaluations.

\subsection{Sample}

To solicit research participants, we first contacted top managers of 25 companies in Taiwan. After receiving permission from each company, one of the authors directly invited $H R$ and line managers who were responsible for conducting employment interviews to participate in this study. In total, 201 middle-level managers agreed to participate. In order to reduce concerns about generalizability (Colquitt, 2008), we deliberately created a heterogeneous sample containing participants from a wide variety of industries (e.g., insurance, electronics, and retailing) and positions (e.g., HR and marketing managers). Participants were informed that the purpose of the study was to gain insight into how selection decisions are made. Eighty-four participants (42\%) were males. All participants had some experience in conducting job interviews $(M=19.73$ times, $S D=34.96)$. The mean age of the participants was 39.13 years $(S D=8.88)$.

\subsection{Procedure}

Multiple experimental sessions were carried out in this study. Upon arriving at the study site, each participant received an information packet that included a job description concerning an entry-level marketing specialist, the applicant's resume, items measuring the interviewer's postinterview evaluation, and the manipulation check items. The information packets were identical in each scenario. Participants were asked to familiarize themselves with the scenario background, the information provided about the job candidate, and their roles as interviewers.

After reviewing the information package, participants were randomly assigned to one of the eight scenarios. They were asked to watch a video of a simulated interview. The type of interviewer negative concerns shown in videos and the ways the applicant responded to the negative concerns varied according to the scenario that the participant was assigned to. Each experimental session was conducted in a group of 3-12 participants. They were told to make their hiring decisions independently. After completing the questionnaire, participants were debriefed and received a gift worth US $\$ 2$ for their participation.

\subsection{Stimulus materials}

Eight versions of video-taped simulated interviews were created. Two of them served as control groups, in which the interviewer raised competence- or integrity-related concerns but the applicant used no defensive IM tactic in response. Six versions 2 (negative concern types) $\times 3$ (defense IM tactics) were created as the experimental groups. Except for the manipulated stimulus, each version contained identical information such as the self-introduction of the applicant and questions and answers related to work motivation, job-related skills, and work attitudes. The job position (i.e., a marketing-specialist position) and the voice of the interviewer shown in the video were identical from one scenario to the next. ${ }^{1}$

We manipulated the type of interviewer negative concern by having the interviewer ask one of two types of questions, one challenging the applicant's competence and the other challenging the applicant's integrity. In the competence condition, the interviewer pointed out that according to the application material, the applicant had not performed well in a required course, 'Marketing Management,' as well as on a TOEIC exam. In the integrity condition, the interviewer stated that she had heard, from a third party, that the applicant had been expelled from the student union for embezzlement. We developed two negative events in the competence situation and one negative event in the integrity situation because pilot studies indicated that this approach helps ensure the equality of the severity of interviewer negative concerns in the two situations. As for the manipulation of applicant defensive $I M$ tactics, depending on the scenario they were assigned to, participants may receive one of three types of applicant responses to the interviewer's challenges. Detailed descriptions of these tactics can be found in Appendix A.

\subsection{Dependent measure}

Five items from Tsai, Chen, and Chiu (2005) were used to measure the interviewer's postinterview evaluation of the applicant. The participants were asked to play the role of the interviewer and to evaluate the applicant on a 6-point Likert scale ranging from $1=$ strongly disagree to $6=$ strongly agree. Sample items included 'I do consider this applicant suitable for hiring into this organization' and 'I would not offer this applicant a job' (reverse scored). Cronbach's $\alpha$ of this measure was .94.

\subsection{Confounding variables}

As the interviewer's evaluation of the applicant may be affected by the severity of interviewer negative concerns (Shapiro, 1991), we used one item to measure the perceived severity of interviewer negative concerns. ('The negative event that the interviewer was concerned about was serious.') To rule out the possible confounding effects of applicant characteristics, we also asked interviewers to report their perception of applicants' physical attractiveness and nonverbal behaviors. Four items, 
Table 1. Descriptive statistics, reliabilities, and correlations among measured variables

\begin{tabular}{|c|c|c|c|c|c|c|c|c|c|}
\hline & $M$ & $S D$ & 1 & 2 & 3 & 4 & 5 & 6 & 7 \\
\hline 1. Interviewer gender & - & - & - & & & & & & \\
\hline 2. Interviewer age & 39.13 & 8.88 & $-.23 * *$ & - & & & & & \\
\hline 3. Interviewer experience & 19.71 & 34.96 & $-.17 *$ & $.15^{*}$ & - & & & & \\
\hline 4. Perceived severity & 4.25 & 1.05 & .04 & .03 & .04 & - & & & \\
\hline 5. Applicant physical attractiveness & 3.87 & 0.71 & -.06 & $.20 * *$ & .07 & .08 & $(72)$ & & \\
\hline 6. Applicant nonverbal behaviors & 4.25 & 0.63 & -.08 & .09 & .11 & .12 & $.59 * *$ & $(73)$ & \\
\hline 7. Interviewer evaluation & 3.74 & 0.99 & -.04 & .08 & .04 & -.11 & $.53 * *$ & $.49 * *$ & (94) \\
\hline
\end{tabular}

Note. Sample size $=201$. Gender was coded 1 for female and 0 for male. Coefficient $\alpha$ reliability estimates are presented in parentheses along the diagonal.

developed by Tsai, Huang, and Yu (2006), were used to measure the participant's perception of applicants' physical attractiveness (e.g., 'I think the applicant's face is attractive' and 'I think the applicant's body is well shaped'). Six items from Tsai et al. (2006) were used to measure the applicant's nonverbal behaviors during the interview (e.g., 'The applicant maintained eye contact at all times' and 'The applicant smiled a lot during the interview'). Participants rated these items on a 6-point Likert scale ranging from $1=$ strongly disagree to $6=$ strongly agree. Cronbach's $\alpha$ was .72 for applicants' physical attractiveness and .73 for nonverbal behaviors in this study. Table 1 presents the means, standard deviations, and intercorrelations of the measured variables of this study.

\section{Results}

\subsection{Manipulation checks}

We created two items to ascertain the success of the type-of-concern manipulation ('The interviewer challenged the applicant's integrity' and 'The interviewer challenged the applicant's competence'). We compared the mean scores on the concern-type manipulation checks across competence and integrity conditions in order to determine whether or not we had successfully manipulated the types of interviewers' negative concerns in the simulated interviews. Participants in the competence condition perceived that the applicant faced a greater challenge from competence issues $(M=5.13, S D=.74)$ than from integrity issues $(M=2.31, S D=.64)$, $t(100)=26.70, p<.01$. Participants in the integrity condition perceived that the interviewer's questions were geared more toward integrity issues $(M=4.93, S D=.66)$ than to competence issues $(M=2.56, S D=.59), t(99)=26.48$, $p<.01$.

We used three items to ascertain the success of the defensive IM manipulation: 'The applicant accepted responsibility for the negative event and promised to avoid repeating it' (apology), 'The applicant admitted this fault, but argued that his or her action was acceptable in that situation' (justification), and 'The applicant did not take responsibility for the event triggering the negative con- cern and attributed the event to external causes' (excuse). We had participants evaluate the degree to which the applicant demonstrated each defensive IM tactic in the interview on a 6-point Likert scale ranging from $1=$ strongly disagree to $6=$ strongly agree. Participants in the experimental groups (those who received defensive IM tactics) both correctly identified the type of IM tactics that the applicant demonstrated in the interview and assigned significantly higher scores to the corresponding tactics than to the other two tactics, $t=3.23-14.88$, all $p s<.01$. Control-group participants reported that the applicant had used few defensive IM tactics during the interview (competence: $M=2.09, S D=.59$; integrity: $M=1.99, S D=.47)$. In addition, the scores of the three defensive IM tactics did not significantly differ from one another in the control groups, $t=0.95,0.83$, and 1.20 , respectively, all $p s>.05$.

Finally, in consideration of the effects of confounding variables, results from a series of analysis of variance (ANOVA) indicated that applicants' physical attractiveness and nonverbal behaviors did not significantly vary from scenario to scenario, $F(7,193)=.32$ and .187 , respectively, $p s>.05$. In addition, participants provided similar evaluations on the perceived severity of interviewers' competence and integrity concerns, $F(7,193)=3.13, p>.05$. Taken together, these results suggest that our manipulations of concern-type and defensive IM were successful. In addition, the three possible confounding variables were properly controlled. This should eliminate alternative explanations for the observed findings.

\subsection{Hypothesis testing}

Table 2 summarized the means and standard deviations of interviewer evaluation in all eight conditions. Results from a one-way ANOVA indicated that the difference of interviewer evaluations was statistically significant between the experimental and control groups, $F(3,197)=$ $8.55, p<.01$. Post hoc analyses (Fisher's LSD test) show that the participants in apology $(M=3.83, S D=.94)$, justification $(M=4.03, S D=.84)$, and excuse $(M=3.92$, $S D=.85)$ conditions provided significantly higher evaluations of the applicant than those in the con- 
Table 2. Means and standard deviations of dependent variables across eight conditions

\begin{tabular}{lllll}
\hline & $\begin{array}{l}\text { Control } \\
\text { group }\end{array}$ & \multicolumn{2}{l}{ Experimental groups } \\
\cline { 3 - 5 } & & Apology & Justification Excuse \\
\hline Overall & $M=3.16$ & $M=3.83$ & $M=4.03$ & $M=3.92$ \\
Competence- & $M=1.12$ & $S D=0.94$ & $S D=0.84$ & $S D=0.85$ \\
related concerns & $S D=1.08$ & $M=4.20$ & $M=4.24$ & $M=3.86$ \\
Integrity-related & $M=3.10$ & $M=3.46$ & $M D=0.93$ & $S D=0.91$ \\
concerns & $S D=1.17$ & $S D=0.90$ & $S D=0.69$ & $S D=3.98$ \\
& $S D$ &
\end{tabular}

Note. Except for the competence-excuse group $(n=26)$, the sample size of each group was 25 .

trol group $(M=3.16, S D=1.12)$, mean difference $d=.67$, .86 , and .76 , respectively, all $p s<.01$. This indicates that when interviewers raised negative concerns, job applicants who used any type of defensive IM tactics would receive better evaluations than those who did not. Thus, Hypothesis 1 was supported.

We also found a significant interaction effect between the type of interviewers' negative concern and defensive IM on interviewer evaluation from a $2 \times 3$ ANOVA, $F(1,145)=2.82, p<.05, \eta^{2}=.04$. Thus, Hypothesis 2 was supported. ${ }^{2}$ Post hoc comparisons were performed to further understand the form of interaction between applicant defensive IM tactics and the types of negative concern. When dealing with competence-related concerns, it was found that apologies $(M=4.20, S D=.86)$, justifications $(M=4.24, S D=.93)$, and excuses $(M=3.86$, $S D=.91$ ) were equally effective, $d=.04-.38, \mathrm{ps}>.05$. In contrast, when an integrity-related issue was under consideration, interviewers reacted more favorably to excuses $(M=3.98, S D=.79)$ than to apologies $(M=3.46$, $S D=.90), d=.52, p<.05$. The effect of justifications $(M=3.82, S D=.69)$ lies in between $(d=-.17$ and .35 , ps $>.05$ ). In addition, results of within-tactic comparisons confirm our speculation that interviewers react to applicant apology tactics more favorably when the concerns are competence related $(M=4.20, S D=.86)$ than when they are integrity related $(M=3.46, S D=.90), d=.98, p<.05$. As for justification and excuse tactics, their effects did not significantly vary across the two concern conditions, $d=.12$ and .42 , respectively, ps $>.05 .^{3}$

It is worth mentioning that applicant characteristics (e.g., gender and physical attractiveness) were not controlled in the preceding analyses because, theoretically, a successful random assignment would rule out the effects of these variables (Highhouse, 2009). We have, however, performed several additional analyses so that readers can gain further information on the role of applicant characteristics in employment interviews. Results showed that applicant gender, nonverbal behaviors, and gender similarity (i.e., whether the applicant and the interviewer were of the same gender or not) were not significantly associated with interviewer evaluation, $F(1,142)=.88$,
.02 , and 1.31 , respectively, $p>.10$, and the inclusion of these variables had no effects on the pattern of our results. Although a significant univariate relationship was found between applicant physical attractiveness and the dependent variable, $F(1,143)=32.61, p<.01$, the model with applicant physical attractiveness included as a covariate produced identical results with that reported above.

\section{Discussion}

The current study examines the effects of three applicant defensive IM tactics on interviewer evaluation (i.e., apologies, justifications, or excuses). Results indicate that, in general, each tactic helps applicants mitigate unfavorable evaluations arising from interviewers' negative concerns. Negative concerns may not surface in each interview, but they cannot be ignored once they do. The social-interaction nature embedded in employment interviews motivates applicants to put their best foot forward. Given that interviewers typically pay more attention to negative information than to positive information about applicants (Rowe, 1989), our results suggest that when an interviewer raises the failure experience of an applicant, the applicant will be better off if employing some kind of defensive IM tactic to protect his or her image.

Perhaps a more interesting finding is that the effectiveness of defensive IM tactics depends on the type of negative concerns the applicant was facing. Although IM has been one of the most prominent emerging research topics in job-interview research in the past decade (Posthuma, Morgeson, \& Campion, 2002), defensive IM - until recently - received far less attention than assertive IM did. To our knowledge, the present study is one of the first studies testing the boundary conditions of defensive IM in the context of job interviews. Results indicate that the effects of applicants' defensive IM tactics depend on a contextual variable, the type of negative concern. For competence-related concerns, all three tactics had similar effects on interviewer evaluations. However, for integrityrelated concerns, excuses may be the best tactic for addressing interviewers' negative concerns. Thus, in addition to examining the effects of individual defensive IM tactics in the context of job interviews, the present study increases our knowledge on how situational factors influence the effectiveness of defensive IM tactics.

We contend that differentiating defensive IM tactics from one another contributes to the literature in more respects than the topic of methodological improvements. The unveiling of each tactic's uniqueness helps confirm or refine the existing theory. For example, from the literature, we know that behavioral description interviews and several personality traits of the applicants (e.g., the altruism facet of agreeableness and locus of control) promote applicants' aggregate usage of defensive IM 
tactics (Peeters \& Lievens, 2006; Van Iddekinge et al., 2007). Bearing in mind that these studies treated various types of defensive IM tactics as a whole rather than individual tactics, significant conceptual improvements can be made if we pay more attention to the uniqueness of each defensive tactic. As the present study found that defensive tactics may have distinct effects on interviewer evaluations, it seems reasonable to predict that these defensive tactics may also be well caused by different antecedents. For example, applicants who hold an internal locus of control may report greater control over outcomes and, thus, are inclined to use more apologies and fewer excuses in explaining their failure experience. Alternatively, applicants who hold an external locus of control are more likely to engage in excuses than in apologies. By doing so, researchers are in effect expanding the nomological network of defensive IM and providing a finer depiction of behaviors in job interviews.

\subsection{Practical implications}

Our results suggest that applicants would be better off using defensive IM tactics to address interviewers' negative concerns. More importantly, although the three defensive IM tactics may produce similar image-repairing effects for competence-related concerns, their effects may differ from one another for integrity-related concerns. Applicants should be careful in their choice of defensive IM tactics, because an inappropriate choice (e.g., using apology tactics in response to integrity-related concerns) might poorly repair an already damaged image.

The results of this study also remind interviewers to carefully verify the accounts offered by applicants. Our results suggest that interviewers are, more often than not, susceptible to applicants' uses of defensive IM tactics. Nonetheless, accountability regarding the applicant-provided accounts can be problematic. An obvious example concerns an applicant who claims that he or she is not responsible for a particular event (i.e., excuses) when he or she is, in fact, responsible for it. Thus, interviewers should try to verify the credibility of the applicant's account (e.g., through reference checks). Alternatively, to reduce the probability of faking, interviewers can warn applicants that their answers will be verified after the interview. Research has shown that warning can mitigate the propensity to fake biodata items (Kluger \& Colella, 1993). It may, as well, reduce applicants' intentions to present false or misleading answers in response to questions concerning the given failure experience.

\subsection{Limitations and future directions}

The present study involved only a single job vacancy in the simulated interviews. Thus, the generalizability of our findings might be limited. The job characteristic may have a twofold implication for the results reported here. The position of marketing specialist is a popular job position in Taiwan's job market and is a common position that can be found in almost every company. Using a job vacancy familiar to the study participant as the experimental stimulus would likely increase the realism of the experiment (Stone-Romero, 2002). In addition, the job vacancy used in this study may resemble a wide variety of jobs, such as clerks and police officers. For these jobs, interviewers would generally agree that both competence and integrity are important criteria in evaluating job candidates. In this light, we believe that the findings of this study can be generalized to jobs other than marketing-specialist jobs.

However, we agree that the level of the job position in the organizational hierarchy could moderate the effect of defensive IM tactics. For example, interviewers may be more lenient on less-skilled applicants who apply for entry-level jobs than on applicants who are less skilled and who apply for advanced positions (e.g., chief engineer or senior accountant). In other words, interviewers' expectations of the applicants can differ significantly, depending on the level of job for which the applicants are applying. This difference may also explain our unexpected findings regarding the lack of difference between the effects of three defensive IM tactics under the competence condition. It is possible that interviewers who participated in this study generally considered that an applicant applying for a marketing-specialist position but lacking the necessary skills and abilities for this entry-level position is tolerable. Therefore, they did not react differently to the three defensive IM tactics once an explanation had been provided for the competence-related concerns. Future research examining additional moderators such as job hierarchy is needed to help clarify when and for whom these tactics would be most effective.

The present study was conducted on the assumption that interviewers' negative concerns damage applicants' positive image and, as a result, weaken applicants' opportunities to be hired. Consequently, we did not include a scenario without any interviewer negative concerns. Although this does not represent a threat to the findings reported here, our study is limited in terms of its ability to assess the extent to which an applicant's defensive IM tactics helped 'repair' the applicant's damaged image. For this reason, we recommend that future studies explicitly compare postinterview evaluations regarding applicants who are facing interviewer negative concerns with postinterview evaluations regarding applicants who are facing no such concerns. Such a study would help to assess the extent to which interviewers' negative concerns affect the interviewers' evaluation. After that, researchers can estimate the degree to which each defensive IM tactic can counteract the negative effects of these concerns.

As the present study was conducted with simulated interviews, some may have concerns about the generalizability of these findings. It should be noted, however, 
that generalizability is subject to a number of factors and should not be judged merely by the surface resemblance between experimental and real situations. For example, it has been argued that an experiment's findings are more generalizable when the operationalization of the constructs allows generalizable inferences (Highhouse, 2009). Accordingly, we operationalized the key constructs, defensive IM tactics, in a way that can be easily extended to other situations in which negative events jeopardize the applicant's desired image (cf. Appendix A for more details). Moreover, in order to increase the 'experimental realism' (Berkowitz \& Donnerstein, 1982), we invited real corporate recruiters to participate in this study and to perform a familiar task (i.e., evaluating the employability of the applicant). Taken together, although the extent to which our findings are generalizable across settings could best be answered by future field research, we believe similar patterns will be found by these studies.

One way to expand the present study is to discover how simultaneous uses of multiple defensive IM tactics affect interviewer evaluations. Is it always preferable to use as many tactics as possible to defend oneself? Will the effects of different defensive IM tactics reinforce or cancel out each other? At present, these questions remain unanswered. It is possible that answers to these questions may involve the mechanism of the effect of each tactic. For example, it has been suggested that successful apologies are likely to reduce negative emotions, while effective justifications and excuses may work in another way - that is, may shift the blame (Ohbuchi, Kameda, \& Agarie, 1989; Tata, 2002a). It would be interesting for future research to examine whether the combination of justifications and apologies (i.e., heterogeneous tactics) works better than that of justifications and excuses (i.e., homogeneous tactics).

Another issue worth investigating is whether the use of highly structured interviews would reduce the effectiveness of defensive IM. Researchers found that highly structured interviews reduce the effects of applicants' nonverbal IM tactics but not the effects of applicants' verbal IM tactics (Tsai et al., 2005). A possible explanation is that interviewers generally consider applicants' verbal IM tactics to be job related. Because interviewers raise their negative concerns, be they competence- or integrity-related issues, to assess the suitability of the candidate for the job, it is reasonable to assume that most interviewers' concerns take the form of job-related questions. As defensive IM tactics are employed by applicants to address interviewers' negative concerns, most of the information contained in defensive IM tactics should as well be considered to be job related. If this is the case, the interview structure would have little effect on the relationship between defensive IM tactics and interviewer evaluations. However, future research is needed to empirically examine this proposition.
In conclusion, compared to applicants' assertive IM tactics, relatively little is known about the antecedents, consequences, and boundary conditions of applicants' defensive IM tactics in the interview context. Our findings extend previous interview research by disentangling the effects of the three defensive IM tactics and by examining the moderating effects that types of interviewer negative concerns have on defensive IM tactics. We feel that more research on this subject is needed to improve our knowledge of how this image-repairing tool works and, thereby, to guide practitioners in conducting employment interviews.

\section{Notes}

1. One female played the role of the interviewer across all scenarios but did not appear visually in the videos. Instead, participants could only hear her voice. To rule out the possibility that the observed effects were due to gender or other personal characteristics of the applicant (i.e., the actor) as opposed to the experimental conditions, we had one male and one female play the role of the applicant in each scenario. They wore gender-appropriate attire and were trained to display a similar demeanor. Participants randomly watched an interview session in which either the male or the female actor served as the applicant. This was done to rule out the possible effect of applicant gender.

2. We have also performed an ANCOVA in which interviewer age and interview experience were entered as covariates. Results showed that neither of these variables reached the traditional significant level, $F(1,143)=.26$ and .17 for interviewer age and interview experience, respectively, $p>.10$. The inclusion of these two variables had virtually no influence on the pattern of our results.

3. We thank an anonymous reviewer for raising an interesting theoretical concern regarding the possible three-way interaction, Effect of Interview Experience $\times$ Types of Negative Concerns $\times$ Defensive IM Tactics. We have performed an additional analysis to test whether experienced interviewers are less easily influenced by applicants' defensive IM tactics in each circumstance. Results showed that the effect of the three-way interaction term was not significant, $F(2,134)=.95$, $p>.10$, suggesting that our findings were applicable to both inexperienced and experienced interviewers.

\section{References}

Berkowitz, L., \& Donnerstein, E. (1982). External validity is more than skin deep: Some answers to criticisms of laboratory experiments. American Psychologist, 37, 245-257.

Bolino, M.C., Kacmar, K.M., Turnley, W.H., \& Gilstrap, J.B. (2008). A multi-level review of impression management motives and behaviors. Journal of Management, 34, 1080-1109.

Bozeman, D.P., \& Kacmar, K.M. (1997). Cybernetic model of impression management processes in organizations. Organizational Behavior and Human Decision Processes, 69, 9-30. 
Butler, J.K., Jr., \& Cantrell, R.S. (1984). A behavioral decision theory approach to modeling dyadic trust in superiors and subordinates. Psychological Reports, 55, 19-28.

Colquitt, J.A. (2008). Publishing laboratory research in AMJ: A question of when, not if. Academy of Management Journal, 51 , 616-620.

Ellis, A.P.J., West, B.J., Ryan, A.M., \& DeShon, R.P. (2002). The use of impression management tactics in structured interviews: A function of question type? Journal of Applied Psychology, 87, 1200-1208.

Fenno, R.F., Jr. (1978). Home style: House members in their districts. Boston, MA: Little, Brown.

Godfrey, D.K., Jones, E.E., \& Lord, C.G. (1986). Self-promotion is not ingratiating. Journal of Personality and Social Psychology, 50, 106-115.

Highhouse, S. (2009). Designing experiments that generalize. Organizational Research Methods, 12, 554-566.

Kacmar, K.M., Delery, J.E., \& Ferris, G.R. (1992). Differential effectiveness of applicant impression management tactics on employment interview decisions. Journal of Applied Social Psychology, 22, 1250-1272.

Kim, P.H., Ferrin, D.L., Cooper, C.D., \& Dirks, K.T. (2004). Removing the shadow of suspicion: The effects of apology versus denial for repairing competence - versus integrity-based trust violations. Journal of Applied Psychology, 89, 104-118.

Kluger, A.N., \& Colella, A. (1993). Beyond the mean bias: The effect of warning against faking on biodata item variances. Personnel Psychology, 46, 763-780.

McCurley, C., \& Mondak, J.J. (1995). Inspected by \#1184063113: The influence of incumbents' competence and integrity in U.S. House elections. American Journal of Political Science, 39 , 864-885.

Ohbuchi, K., Kameda, M., \& Agarie, N. (1989). Apology as aggression control: Its role in mediating appraisal of and response to harm. Journal of Personality and Social Psychology, 52, 219-227.

Ones, D.S., Viswesvaran, C., \& Schmidt, F.L. (1993). Comprehensive meta-analysis of integrity test validities: Findings and implications for personnel selection and theories of job performance. Journal of Applied Psychology, 78, 679-703.

Peeters, H., \& Lievens, F. (2006). Verbal and nonverbal impression management tactics in behavior description and situational interviews. International Journal of Selection and Assessment, 14, 206-222.

Posthuma, R.A., Morgeson, F.P., \& Campion, M.A. (2002). Beyond employment interview validity: A comprehensive narrative review of recent research and trends over time. Personnel Psychology, 55, 1-81.

Reeder, G.D., \& Brewer, M.B. (1979). A schematic model of dispositional attribution. Psychological Review, 86, 61-79.

Roberts, L.M. (2005). Changing faces: Professional image construction in diverse organizational settings. Academy of Management Review, 30, 685-711.

Rowe, P.M. (1989). Unfavorable information and interview decisions. In R.W. Eder, \& G.R. Ferris (Eds.), The employment interview: Theory, research, and practice (pp. 127-141). Newbury Park, CA: Sage.

Schweitzer, M.E., Hershey, J.C., \& Bradlow, E.T. (2006). Promises and lies: Restoring violated trust. Organizational Behavior and Human Decision Processes, 101, 1-19.
Shapiro, D.L. (1991). The effects of explanations on negative reactions to deceit. Administrative Science Quarterly, 36, 614-630.

Shaw, J.C., Wild, E., \& Colquitt, J.A. (2003). To justify or excuse? A meta-analytic review of the effects of explanations. Journal of Applied Psychology, 88, 444-458.

Stevens, C.L., \& Kristof, A.L. (1995). Making the right impression: A field study of applicant impression management during job interviews. Journal of Applied Psychology, 80, 587-606.

Stone-Romero, E.F. (2002). The relative validity and usefulness of various empirical research designs. In S.G. Rogelberg (Ed.), Handbook of research methods in industrial and organizational psychology (pp. 77-98). Malden, MA: Blackwell.

Tata, J. (2000). She said, he said. The influence of remedial accounts on third-party judgments of coworker sexual harassment. Journal of Management, 26, 1133-1156.

Tata, J. (2002a). The influence of accounts on perceived social loafing in work teams. The International Journal of Conflict Management, 13, 292-308.

Tata, J. (2002b). The influence of managerial accounts on employees' reactions to negative feedback. Group and Organization Management, 27, 480-503.

Tsai, W.C., Chen, C.C., \& Chiu, S.F. (2005). Exploring boundaries of the effects of applicant impression management tactics in job interviews. Journal of Management, 31, 108-125.

Tsai, W.C., Huang, T.C., \& Yu, H.H. (2006, July). Interviewer responses to applicant physical attractiveness and non-verbal behavior: A field study of moderating effects of interviewer fit perception of job sex-type and customer-contact requirements. Paper presented at the 26th International Congress of Applied Psychology, Athens, Greece.

Van Iddekinge, C.H., McFarland, L.A., \& Raymark, P.H. (2007). Antecedents of impression management use and effectiveness in a structured interview. Journal of Management, 33, 752-773.

Wayne, S.J., \& Liden, R.C. (1995). Effects of impression management on performance ratings: A longitudinal study. Academy of Management Journal, 38, 232-260.

\section{Appendix A}

\section{Apologies in the competence condition}

'It was my fault. Too many extracurricular activities took up too much of my time for study.... However, I soon noticed that I should not sacrifice my course work for sports events or theatrical productions. I was sorry for not spending enough time studying and I decided to concentrate more on my studies .... As for the TOEIC exam, I have to say, I vastly overestimated my listening skills. When I got my exam results, I couldn't help thinking if I had tried harder, things would've been different .... After that, I made a big effort to improve my listening skills. l've also learned a lesson that one reaps no more than what one has sown. Having this experience helps me avoid similar mistakes.' 


\section{Justifications in the competence condition}

'My Marketing Management teacher was quite unreasonable and set a harsh standard for this course .... Although I got a B-, I was actually at the head of the class. About half of my classmates failed. In this sense, my grade was better than it appeared to be .... As for the TOEIC exam, I think the score of a paper-and-pencil test cannot represent my English skills. I have no problem talking to people in English. I just get nervous easily in tests .... There is no need to worry about it.'

\section{Excuses in the competence condition}

'I got a B- in Marketing Management because the bus I took that day got a flat tire about half the way to my school. Therefore, I was late for the exam by more than fifteen minutes .... I could have done better if the bus driver had double checked the tire before hitting the road .... As for the TOEIC exam, I was a victim of some terrible malfunction of the test equipment. For example, I could hardly hear anything out of my earphone .... The grades did not reflect my English skills at all. I am sure I have no problem communicating with people in English.'

\section{Apologies in the integrity condition}

'I was once in charge of handling the membership fees of the student union .... Right before my junior year, I lost my part-time job. Hence, I took some money from the union to pay my tuition .... Although I managed to return the money a few months later, someone in the union discovered my mistake .... I am profoundly regretful for my violation of people's trust. I know that I cannot go back in time, but I have sworn to myself I will never do anything like that again.'

\section{Justifications in the integrity condition}

'Yes, I was once in charge of handling the membership fees of the student union .... On the one hand, I had to suffer through a lot of red tape to allocate the money. On the other hand, union activities can be costly and way over budget .... There were always tensions between principle and expediency. Sometimes I had no choice but to draw on union funds without permission .... What I did may be questionable, but it should not be considered embezzling.'

\section{Excuses in the integrity condition}

'It is not my fault. I was set up! I was in charge of handling the membership fees of the student union. Some people really didn't like me because I did everything by the book. I believe someone stole the money in order to get me replaced .... l've tried to defend myself, but no one would listen .... In the end, I was expelled from the union for the embezzlement that I didn't commit. I was just the scapegoat in this event.' 